\title{
The evolution of headache from childhood to adulthood: a review of the literature
}

\author{
Fabio Antonaci ${ }^{1 *}$, Cristina Voiticovschi-losob ${ }^{2,3}$, Anna Luisia Di Stefano ${ }^{4}$, Federica Galli ${ }^{1}$, Aynur Ozge ${ }^{5}$ and \\ Umberto Balottin ${ }^{1,6}$
}

\begin{abstract}
Headache is one of the most common disorders in childhood, with an estimated $75 \%$ of children reporting significant headache by the age of 15 years. Pediatric migraine is the most frequent recurrent headache disorder, occurring in up to $28 \%$ of older teenagers. Headaches rank third among the illness-related causes of school absenteeism and result in substantial psychosocial impairment among pediatric patients.

The aim of this study was to clarify the evolution of the clinical features of primary headache in the transition from childhood to adulthood through a review of relevant data available in the PubMed and Google Scholar databases for the period 1988 to July 2013.

The search strategy identified 15 published articles which were considered eligible for inclusion in the analysis (i.e. relevant to the investigation of pediatric headache outcome). All were carried out after the publication of the first version of the International Classification of Headache Disorders (ICHD-I).

The availability of data on the evolution of primary headaches over a period of time is important from both a clinical and a public health perspective. The identification of prognostic factors of the evolution of headache (remission or evolution into another headache form) over time should be an objective of future headache research for the development of prevention strategies. Given that headache is a major factor contributing to school absenteeism and poorer quality of life not only in childhood but also in adolescence, understanding the natural history and the management of the different headache forms is vital for our future.
\end{abstract}

Keywords: Migraine; Tension-type headache; Cluster headache; Childhood; Adolescence; Evolution

\section{Introduction}

The first description of the different types and clinical characteristics of headache in children was probably that provided by Vahlquist in 1949 [1]. Headache is one of the most common disorders in childhood, with an estimated $75 \%$ of children reporting significant headache by the age of 15 years [2]. Headache is rare before the age of 4, but its prevalence increases throughout childhood, peaking at around 13 years of age in both sexes. Prevalence estimates vary according to age, the definition of headache and the method of data collection used, but as many as $75 \%$ of school-age children may experience headache infrequently, while around $10 \%$ have recurring headaches $[3,4]$. Studies using the first International Headache

\footnotetext{
* Correspondence: fabio.antonaci@unipv.it

${ }^{1}$ Headache Center, C. Mondino National Institute of Neurology Foundation, IRCCS, University of Pavia, Pavia, Italy

Full list of author information is available at the end of the article
}

Society criteria (IHS, 1988) found prevalence rates of between 3 and $11 \%$ in the general population $[5,6]$.

Migraine is a frequent disease with a prevalence of 3$10 \%$ in children and adolescents $[7,8]$. Epidemiological data on tension-type headache (TTH) in young subjects have become available only in the last decade and suggest prevalence rates of between 10 and 24\% [9].

Only about $5-10 \%$ of cluster headache $(\mathrm{CH})$ patients developed the disease in adolescence, while onset of $\mathrm{CH}$ in childhood is very rare [10]. Over the last few years, there has been a growing interest in the evolution of $\mathrm{CH}$ over time [11].

Recurrent primary headaches may have a considerable impact on the quality of life of children and adolescents due to the unpredictability of attacks and the presence of accompanying symptoms such as nausea, vomiting, photo and/or phonophobia [12]. Headache in childhood is associated with several psychopathological factors; 
evaluated prospectively, children with frequent headache were found to have an increased risk of headache, multiple physical symptoms and psychiatric morbidity in adulthood [3]. Reports have shown an association between headache in childhood and several psychosocial factors, such as maternal depression, depression in childhood, social disadvantage and coming from a family with a history of "painful conditions" [13]. Patients with migraine have been found to show more psychopathological symptoms than healthy controls [5]; TTH patients also had more psychopathology than controls, although the difference was more marked in the area of Internalizing disorders [5].

Headache in children and adolescents can lead to impaired psychosocial functioning in various areas of life including family, leisure time activities, working capacity and productivity at school [14]. In addition, affected youngsters may be at a heightened risk of developing additional physical problems in adulthood, as well as mental difficulties such as anxiety and depression [15]. Headaches rank third among illness-related causes of school absenteeism and result in substantial functional impairment among pediatric patients [16].

These data underline the importance of improving understanding of how headache evolves through to adulthood, how its clinical features change, and whether it is possible to identify prognostic factors that indicate whether a patient's condition (frequency and duration of attacks and symptomatology) is likely to improve, remain unchanged, worsen, evolve into another type of headache, or disappear.

The aim of this study was to review all published data, available in the PubMed and Google Scholar databases, relating to the evolution of the clinical features of headache during the transition from childhood to adulthood.

\section{Review \\ Methods}

We searched the PubMed database for literature published between 1988 and July 2013 on the evolution of clinical features of headache from childhood to adulthood. The search was performed using the following combination of terms: "migraine headache" OR "tension-type headache" OR "cluster headache" OR "trigeminal autonomic cephalalgias" OR "paroxysmal hemicranias" AND "evolution" OR "childhood" OR "adolescence". We also searched Google Scholar, and cross-referenced recent review articles on childhood headache and migraine. Only articles in English and performed in accordance with the diagnostic criteria of the IHS classification [17] were included.

\section{Results}

The search strategy identified 15 published articles that were considered eligible, i.e. relevant to investigation of the outcome of childhood headache; all were included in the analysis.

\section{Epidemiology of headache}

Several studies have been conducted to define the epidemiology of headache in children [6]. Headache disorders in children and adolescents have a high incidence and prevalence, and are also associated with high costs, both to the individual concerned and to society [18]. The reported prevalence of headache among schoolchildren varies greatly, ranging from 5.9 to $82 \%$, depending on the definitions and inclusion criteria used $[1,7,18,19]$. The vast majority of headaches in this age group are primary and classified as migraine or TTH. The prevalence of headache increases throughout childhood, peaking at about 11-13 years of age in both sexes [3]. Headache is reported in $3-8 \%$ of children at 3 years of age $[13,20]$, in $19.5 \%$ at the age of 5 , and in $37-51.5 \%$ at the age of 7 [8,21-24]. The prevalence of headache in $7-15$ year-olds ranges from 26 to $82 \%[8,23,25]$. In the study of headache and migraine prevalence in children and adolescents conducted by Abu-Arafeh et al. [26], the estimated prevalence of headache over periods of between one month and lifetime was found to be $58.4 \%$, while the prevalence of migraine over periods ranging from six months to lifetime was $7.7 \%$. Bille et al. [2] studied headache prevalence according to age and found the following distribution: $5.9-37.7 \%$ at preschool age, 39\% at 6 years, and $70 \%$ at 15 years, while the findings of Stewart et al. [27] indicated the following age-distributed prevalence of migraine: $3 \%$ in children between $3-$ 7 years, $4-11 \%$ in those aged $7-11$ years, and $8-23 \%$ in 11-15 year olds. In addition, the median age at onset was estimated to be 7.2 years in males and 10.9 years in females. Epidemiological data on TTH in young subjects suggest prevalence rates of between 10 and 24\% [9]. The earliest publications on $\mathrm{CH}$ in childhood date back to the 1970s [28,29] and in 1980, an interesting description of cluster symptoms in an infant was published [30]. The past decade has seen few published reports on the outcome of childhood $\mathrm{CH}$. A study by Lampl et al. [31] found childhood onset (11-18 years) of $\mathrm{CH}$ to have a prevalence of $0-1 \%$.

Paroxysmal hemicrania $(\mathrm{PH})$ is a rare headache with a prevalence of $0.02 \%$ [32]. Relatively few pediatric cases have been reported in the literature. Children as young as 3 years of age have reportedly been diagnosed with the disorder [33-35]. Similarly, SUNCT (short-lasting unilateral neuralgiform headache attacks with conjunctival injection and tearing) is an extremely rare disorder in children with very few cases reported in the literature [36]. No data are available about the evolution of these disorders following their observation in children. 


\section{Evolution of the temporal pattern of migraine and tension-type headache over time (Table 1)}

Guidetti and Galli [15,37] conducted a long-term prospective study in which 100 subjects (60 females, 40 males aged 12-26 years with a mean age of 17.9 years) were examined in 1988 and then re-evaluated in 1996, in order to ascertain the evolution of migraine and TTH after an eight-year interval. Of the 100 patients seen at the eight-year follow-up, 45\% showed an improvement and $34 \%$ were headache free, whereas the clinical pattern was unchanged in $15 \%$. The remaining $6 \%$ presented a worsening of headache. Migraine showed a lower tendency to remit compared with TTH (28.1\% vs $44.4 \%)$. Headache prognosis was found to be mostly gender related, with the males showing a higher rate of headache remission than the females $(52.5 \%$ vs $21.7 \%)$. It was concluded that the characteristics early-onset headache tend to change over time, and that early-onset forms have a high tendency to remit or to improve (15).

Hernandez-Latorre et al. [38], in a 10-year prospective longitudinal study of 181 migrainous children, evaluated the possible existence of markers of favorable and unfavorable evolution. In $24 \%$ of the children, the onset of migraine had occurred before the age of 6 years, while in $57 \%$ it had occurred between 6 and 10 years of age. It was concluded that the proportion of patients whose headache showed a favorable evolution was higher among those whose symptoms appeared after the age of 6 years than among those in whom the disease started earlier. Children with headache beginning before the age of 6 were found to have a 4.2 times greater risk of an unfavorable evolution than those whose symptoms appeared between 6 and 10 years of age. Eighty-eight percent of the patients showed a favorable clinical course, while $12 \%$ had to be placed on prophylactic treatment due to increase of their headaches.

Brna and coworkers [39] also conducted a long-term prospective study evaluating the prognosis of childhood headache. Ninety-five percent of their series of headache patients were first studied in 1983 and interviewed after 10 and 20 years (mean follow-up $20.1 \pm 0.4$ years). The mean age at diagnosis was $11.1 \pm 3.0$ years, with a maleto-female ratio of 1:4. Improvement of headache was found in $66 \%$ of the patients included in this study and TTH was found to be more likely than migraine to remit. Headache severity at diagnosis was predictive of headache outcome at 20 years. Of the patients with mild headache at diagnosis, nine (45\%) were headache free at 20 years; of those with moderate or severe headache at diagnosis, seven (18\%) were headache free 20 years later while the other 29 (72\%) were still affected by moderate or severe headache. The provoking factors most commonly reported at 20-year follow-up were: stress (32\%), sleep deprivation (13\%), bright light (13\%), and certain foods (10\%). Associated headache symptoms were common in patients with migraine and TTH. Thirty-eight percent reported motion sickness at 20-year follow-up vs $23 \%$ at 10 years. Only one patient had somnambulism at the 10-year follow-up. The rushes sensory disturbance was reported in $13 \%$ at 20 years and in $17 \%$ at 10 years, whereas the Alice in Wonderland syndrome occurred in $7 \%$ at 20 years and in $10 \%$ at 10 years.

As regards the evolution of early-onset idiopathic headache over time, our group published a prospective evaluation of 25 headache patients referred before the age of 6 years and evaluated through a long-term clinical follow up (mean duration 4.2 years) [40]. In this study headache diagnosis was based not only on the HIS 1988 and ICHD-II criteria [41], but also on "alternative" clinical criteria: duration $<1$ hour in migraine without aura and $<30$ minutes in TTH. The influence of early somatic disorders, "life events", and psychiatric disorders on the onset and course of headache were investigated. At the end of follow-up headache persistence was associated with early detection of somatic disorders and the presence of psychiatric disorders. No significant role was found for gender, history of headache in family members, headache diagnosis at onset or psychiatric comorbidity at first headache center visit.

Another long-term prospective study was published in 2006 by Kienbacher et al. [12]. These authors evaluated children and adolescents with migraine and $\mathrm{TTH}$, in order to investigate the evolution, over time, of their clinical features and headache diagnosis. The study included 227 patients (52.5\% female, $47.6 \%$ male) approximately 6.6 years after their first consultation at a headache center. Of the 140 patients initially diagnosed with migraine, $25.7 \%$ were headache free, $48.6 \%$ still had migraine, and $25.7 \%$ had TTH at the end of the followup. Of the 87 patients initially diagnosed with TTH, $37.9 \%$ were headache free, $41.4 \%$ still had TTH, and $20.7 \%$ had migraine. Consequently, it was shown that $30 \%$ of children and adolescents consulting a headache center because of migraine or TTH become headache free in the long term, while 20-25\% switch from migraine to TTH or vice versa. Female gender, and a longer time between headache onset and first headache center visit tended to predict an unfavorable outcome; while changing headache location at baseline and long clinical follow-up of headache seemed to be favorable prognostic factors. Of the 34 patients with chronic daily headache, including eight with chronic migraine, four with probable chronic migraine, 15 with chronic TTH and seven with probable chronic TTH, 31 (91\%) had a favorable outcome: 12 became headache free, 14 had headache on $\leq 4$ days per month, and five patients had headache on 5-12 days.

Kelman and coworkers [42] evaluated the influence of age on migraine features in a cross-sectional study of 
Table 1 Summary of the evolution of the temporal pattern of headache in children ( $\mathrm{M}=$ migraine, $\mathrm{TTH}=$ tension-type headache; $\mathrm{CH}=\mathrm{cluster}$ headache)

\begin{tabular}{lll}
\hline $\begin{array}{l}\text { Authors } \\
\text { (year) }\end{array}$ & Type of study & Ages \\
\hline Guidetti & prospective, 8-year follow- & age 12-26 yrs., (mean age
\end{tabular}

$\begin{array}{lll}\text { Guidetti } & \text { prospective, 8-year follow- } & \text { age 12-26 } \\ \text { et al. [15] } & \text { up } & 17.9 \mathrm{yrs} .\end{array}$

Hernandez- $\quad 10$-year prospective $\quad>6 \geq 10 \mathrm{yrs}$.

Latorre longitudinal study

et al. [38]

Brna et al. prospective, 20-year follow- mean age 11.1 yrs. [39]

Balottin

et al. [40]

Kienbacher

et al. [12]

Kelman

et al. [42]

cross- sectional study, retrospective analysis

mean age $37.7 \pm 11.7 \mathrm{yrs}$

Virtanen et al. [43] prospective, controlled study

$6-13$ yrs

Gaßman et al. [44] prospective, 4-year longitu- 8-15 yrs dinal study
$\mathrm{M}, \mathrm{TTH}$

\section{Headache Headache evolution}

type

- $26.5 \%$ of the patients with $\mathrm{M}$ changed to TTH

- $8.3 \%$ with TTH changed to $\mathrm{M}$.

- 45\% showed improvement, 34\% were headache free,

$15 \%$ unchanged, $6 \%$ worsened.

$M, T H$

THH $\quad-66 \%$ improvement

- $88 \%$ favorable clinical course; $12 \%$ placed on prophylactic treatment.

- more TTH remission

- $45 \%$ with mild headaches were headache free at 20 years;

- $18 \%$ with moderate/severe headaches were headache free at $20 \mathrm{yrs}$

- $72 \%$ with moderate/severe headaches continued to have moderate or severe headaches at $20 \mathrm{yrs}$.

$\mathrm{M}, \mathrm{TTH} \quad$ - headache persistence in the minority of cases associated with detection of somatic and psychiatric disorders.

M. TTH $\quad-25.7 \%$ were headache free, $48.6 \%$ still $M$ and $25.7 \%$ still TTH at the follow-up.

new headache triggers: hormones, alcohol, smoking, neck pain

- shift in headache location toward the neck.

- increase in rhinorrhea and lacrimation

- $1 / 2$ of $M$ unchanged at $6 \mathrm{yrs} ; 32 \%$ changed to TTH.

- TTH unchanged in 35\%; 38\% changed to $\mathrm{M}$.

- at preschool age the location of headache was bilateral and

- supraorbital; at puberty bilateral and temporal.

- M more frequent in girls than boys, and this difference increased significantly with age.

- TTH dropped from 57\% among 8-year-olds to 45.6\% among 15-year-olds.
Other symptoms, findings

- high rate of headache remission in males.

triggers of headache: stress, sleep deprivation, bright ight, certain foods.

-38\% motion sickness

$-13 \%$ rushes sensory disturbance

- 7\% Alice in Wonderland syndrome

- unfavorable outcome: longer time between headache onset and first consultation

- good prognosis: changing headache location at baseline and long clinical follow-up

- stress as a trigger, photophobia, phonophobia and dizziness, decrease with age

- decrease in the strength of attacks, and reduced need to sleep or rest during headache

osmophobia, dizziness and balance disturbances became more typical with age

- restlessness, flushing and abdominal symptoms became less marked. 
Table 1 Summary of the evolution of the temporal pattern of headache in children $(\mathrm{M}=$ migraine, $\mathrm{TTH}=$ tension-type headache; $\mathrm{CH}=\mathrm{cluster}$ headache) (Continued)

\begin{tabular}{|c|c|c|c|c|c|}
\hline & & & & - $\mathrm{M}$ increased with age from 10 to $17.1 \%$ & \\
\hline \multirow[t]{5}{*}{$\begin{array}{l}\text { Slater et al. } \\
{[45]}\end{array}$} & \multirow[t]{5}{*}{ prospective, retrospective } & \multirow[t]{5}{*}{ mean age $11.7 \pm 3.6$} & \multirow[t]{5}{*}{ M } & - early onset of headache in boys & $\begin{array}{l}\text { - higher levels of disability as shown by PedMIDAS and } \\
\text { no. of missed schooldays in girls. }\end{array}$ \\
\hline & & & & $\begin{array}{l}\text { - boys' headache: squeezing at the top of the head; } \\
\text { sharp pain at the back of the head }\end{array}$ & \multirow[t]{4}{*}{ - older children were more disabled. } \\
\hline & & & & $\begin{array}{l}\text { - girls reported frontal and temporal headache, and } \\
\text { pain in the back of the head; pain: throbbing, pressure, } \\
\text { constant and sharp. }\end{array}$ & \\
\hline & & & & $\begin{array}{l}\text { - girls experienced more frequent and longer mean } \\
\text { duration of headaches. }\end{array}$ & \\
\hline & & & & - older children reported greater headache frequency. & \\
\hline \multirow[t]{4}{*}{$\begin{array}{l}\text { Ozge et al. } \\
{[46]}\end{array}$} & \multirow[t]{4}{*}{$\begin{array}{l}\text { prospective, longitudinal, } \\
\text { school-based six-year inter- } \\
\text { val analysis }\end{array}$} & \multirow[t]{4}{*}{$\begin{array}{l}\text { 8-18 } 5562 \text { children of } \\
\text { whom } 1155 \text { followed up } \\
\text { as adolescents }\end{array}$} & \multirow[t]{4}{*}{$\mathrm{M}, \mathrm{TTH}$} & $\begin{array}{l}\text { - childhood headache persists in adolescence, } \\
\text { although the diagnoses mostly }(71.3 \%) \text { changed over } \\
\text { time. }\end{array}$ & $\begin{array}{l}\text { - PedMIDAS score higher in subjects with parents with } \\
\text { headache history }\end{array}$ \\
\hline & & & & $\begin{array}{l}\text { - M prevalence increased from } 10.4 \% \text { in childhood to } \\
18.6 \% \text { to adolescence in the same study sample after a } \\
6 \text {-year interval. }\end{array}$ & \multirow[t]{3}{*}{$\begin{array}{l}\text { - No supportive correlation with BMI MOH frequency } \\
13.0 \% \text { with migraine and high PedMIDAS score } \\
\text { predominance }\end{array}$} \\
\hline & & & & $\begin{array}{l}\text { - Headache prevalence increased with advancing age, } \\
\text { especially in females; stress factors were the most } \\
\text { important determinants. }\end{array}$ & \\
\hline & & & & $\begin{array}{l}\text { - M negatively affects daily living activities in } \\
\text { adolescents. }\end{array}$ & \\
\hline \multirow{3}{*}{$\begin{array}{l}\text { Wöber- } \\
\text { Bingol et al. } \\
\text { [47] }\end{array}$} & \multirow[t]{3}{*}{$\begin{array}{l}\text { cross- sectional study, } \\
\text { retrospective analysis }\end{array}$} & \multirow[t]{3}{*}{ 3- 69 yrs } & \multirow{3}{*}{$\begin{array}{l}\text { M with or } \\
\text { without } \\
\text { aura }\end{array}$} & $\begin{array}{l}\text { - decrease in headache prevalence from childhood to } \\
\text { adulthood in males }\end{array}$ & \multirow[t]{3}{*}{$\begin{array}{l}\text { - aggravation by physical activity found to be decreased } \\
\text { with age. }\end{array}$} \\
\hline & & & & \multirow{2}{*}{$\begin{array}{l}\text { - increasing of headache duration with age, prevalence } \\
\text { of unilateral and pulsating pain, photo and } \\
\text { phonophobia in girls. }\end{array}$} & \\
\hline & & & & & \\
\hline \multirow[t]{5}{*}{$\begin{array}{l}\text { Maytal et al. } \\
{[10]}\end{array}$} & \multirow[t]{5}{*}{ retrospective } & \multirow[t]{5}{*}{18 yrs or younger } & \multirow[t]{5}{*}{$\mathrm{CH}$} & $\begin{array}{l}\text { - clinical features of } \mathrm{CH} \text { in childhood similar to those in } \\
\text { adults. }\end{array}$ & \multirow[t]{5}{*}{$\begin{array}{l}\text {-changes in associated symptoms over the years in a } \\
\text { small number of patients }\end{array}$} \\
\hline & & & & $\begin{array}{l}\text { - increase in frequency and duration of cluster periods } \\
\text { with age in } 40 \% \text {. }\end{array}$ & \\
\hline & & & & - decrease in duration of cluster periods in $6 \%$ & \\
\hline & & & & $\begin{array}{l}\text { - short cluster periods in } 23 \% \text { of patients in childhood } \\
\text { and in } 6 \% \text { of patients in adulthood. }\end{array}$ & \\
\hline & & & & - $\mathrm{CH}$ shifted sides in one patient. & \\
\hline \multirow[t]{3}{*}{ Lampl [31] } & \multirow{3}{*}{$\begin{array}{l}\text { epidemiological }+1 \text { case } \\
\text { report }\end{array}$} & \multirow[t]{3}{*}{7 years } & \multirow[t]{3}{*}{$\mathrm{CH}$} & - no data about evolution of headache & \multirow{3}{*}{$\begin{array}{l}\text { - no differences between childhood and adolescent } \mathrm{CH} \\
\text { with regard to type of pain, associated symptoms and } \\
\text { predominance in males. }\end{array}$} \\
\hline & & & & $\begin{array}{l}\text { - frequency and duration may increase or remain } \\
\text { unchanged over time if pts are untreated }\end{array}$ & \\
\hline & & & & $\begin{array}{l}\text { - although brief remissions may occur, spontaneous } \\
\text { resolution of } \mathrm{CH} \text { is rare. }\end{array}$ & \\
\hline
\end{tabular}


Table 1 Summary of the evolution of the temporal pattern of headache in children $(\mathrm{M}=$ migraine, $\mathrm{TTH}=$ tension-type headache; $\mathrm{CH}=\mathrm{cluster}$ headache $)$ (Continued)

\begin{tabular}{|c|c|c|c|c|}
\hline \multirow[t]{2}{*}{$\begin{array}{l}\text { Antonaci } \\
\text { et al., [48] }\end{array}$} & $\begin{array}{l}\text { case report and literature } \\
\text { review }\end{array}$ & $\begin{array}{l}\text { case of an 11-year-old } \\
\text { boy }\end{array}$ & $\mathrm{CH}$ & $\begin{array}{l}\text { - first bout } 8 \text { months; second bout } 2 \text { months, with the } \\
\text { same pain characteristics. }\end{array}$ \\
\hline & & & & - this patient as a 'variant'clinical picture \\
\hline \multirow[t]{3}{*}{$\begin{array}{l}\text { Arruda et al. } \\
\text { [49] }\end{array}$} & prospective case report & 9,12 and 13 yrs & $\mathrm{CH}$ & $\begin{array}{l}\text { - no differences between childhood and adult } \mathrm{CH} \\
\text { regarding frequency and duration }\end{array}$ \\
\hline & & & & - good response to indomethacin in two cases; \\
\hline & & & & $\begin{array}{l}\text { - sustained long-term medical and/or spontaneous re- } \\
\text { mission occurred in two patients. }\end{array}$ \\
\hline
\end{tabular}


1009 patients, divided into three age groups: 16-29 years, 30-49 years, and 50 years and over. They found that stress (as a trigger), photophobia, phonophobia and dizziness (as accompanying symptoms) declined with age; moreover, the severity of headache and the need to sleep or rest during attacks also decreased with age. In some cases, increasing age introduced new headache triggers, such as hormones (this factor peaked in women aged 3049 years), alcohol, smoking and neck pain, while the location of the headache shifted towards the neck. Another change with age was an increase in certain symptoms associated with headache: rhinorrhea and lacrimation.

Virtanen et al. [43] in a prospective study evaluated changes in headache from preschool age to puberty. Finnish families $(\mathrm{n}=1132)$ with a 6 -year-old child were questioned. Children affected by headache in the previous six months and their controls were clinically examined at the age of 6 and followed up at the age 13 years. During the follow-up, half of the headaches originally classified as migraine at age 6 years remained unchanged while $32 \%$ turned into TTH. In the children with $\mathrm{TTH}$ at 6 years, the situation remained unchanged in 35\%, while $38 \%$ switched to migraine. The most common headache locations were bilateral and supraorbital at preschool age and bilateral and temporal at puberty. During the follow-up, symptoms accompanying headache, such as osmophobia, dizziness and balance disturbances, became more typical, whereas restlessness, flushing and abdominal symptoms became less marked.

In a four-year longitudinal study of pediatric headache in children and adolescents aged 7-14 years, Gassmann et al. [44] analyzed headache prevalence and evolution. The sample consisted of 8800 households with a child aged between 7 and 14 years. A total of 4159 households responded in both year 1 and year 2, yielding 3984 valid parent questionnaires. In more than half of the children and adolescents with headache (57.0\%), the frequency of head pain remained stable over the one-year period, while improved and worsened frequency of occurrence were found in $22.3 \%$ and $20.7 \%$ of subjects, respectively. Girls experienced migraine more often than boys, and this difference increased significantly with age. At the age of 15 years, the prevalence of migraine in girls was nearly twice that recorded in boys. The proportion of children with TTH decreased with age, from 57\% in 8-yearolds to $45.6 \%$ in 15 -year-olds. The proportion of subjects with migraine increased with age from 10 to $17.1 \%$.

Slater et al. [45] performed a prospective study of 4121 pediatric headache patients. They assessed headache characteristics at an initial consultation and subsequently re-examined the patients at five follow-up visits. A retrospective analysis of the data was completed considering all the patients who completed the questionnaires between January 1998 and October
2007. Fifty-eight percent of the sample were females. Several gender-related differences in the pediatric headache profile were found: the boys began to have headache earlier (mean age: $10 \mathrm{yrs}$ ) than the girls (mean age: $12.5 \mathrm{yrs}$ ); the boys more frequently described "squeezing" headache pain and more frequently reported pain located in the "top of the head" and sharp headache pain located at the back of the head. The girls were more likely to report frontal pain, temporal, pain and pain in the back of the head. They also more frequently described their headache pain as "throbbing", "pressure", "constant" and "sharp". The girls experienced more frequent attacks and headaches with a longer mean duration compared with the boys. Older children reported greater headache frequency than did younger children. Girls showed higher levels of disability than boys considering both PedMIDAS score and number of school days missed. The older a child was at the initial visit, the higher the PedMIDAS score, meaning that the older children were more disabled by headache. According to the ICHD-II criteria (42), the majority of these patients had a diagnosis of migraine $(91.1 \%)$, mostly without aura (78\%). Fourteen percent had chronic migraine. Non-primary headaches were found in $1.6 \%$, with $1.1 \%$ of these being posttraumatic.

In a broad, school-based, epidemiological follow-up study, Ozge et al. evaluated the natural history of migraine and TTH in children and adolescents using a validated headache questionnaire filled in under the supervision of a neurologist [46]. The initial sample of this study comprised 5562 children (10.4\% migraine, $24.0 \% \mathrm{TTH})$; after an interval of six years, 1155 of these subjects subsequently studied as adolescents (18.6\% migraine, $57.5 \% \mathrm{TTH})$. The main finding after the six-year interval was a high rate $(71.3 \%)$ of variations in primary headache diagnosis with increasing age. Only $14.2 \%$ of the TTH and $16.5 \%$ of the migraine subjects were headache free at follow up. However, $56.6 \%$ of the sample had a new TTH diagnosis and $16.9 \%$ a new migraine diagnosis compared to childhood. In total, only $25.3 \%$ of the Turkish schoolchildren considered in this study became headache free. This study highlights the importance of changing and disturbing aspects of primary headache diagnoses with increasing age of the same patient group contributing to associate different headache phenotype.

Wöber-Bingöl et al. [47], in a cross-sectional study, examined 260 patients aged between 3 and 69 years. The case series included 169 females and 91 males suffering from migraine with or without aura. The prevalence of headache in the males was found to decrease markedly from childhood to adulthood. In the females, headache duration and the prevalence of unilateral, pulsating pain, photophobia and phonophobia increased. On the other 
hand, the prevalence of aggravation by physical activity decreased with age. Age-related differences in the clinical features of migraine were observed in the females, but could not be demonstrated in the males due to the relatively small number of men with migraine. Aura symptoms were found most often in the subjects aged 15-40 years and less often in the younger and older patients; the prevalence of aura symptoms did not differ between the males and females.

\section{Evolution of the temporal pattern of cluster headache over time}

Both $\mathrm{CH}$ and the trigeminal autonomic cephalalgias are characterized clinically by repetitive attacks of intense headache accompanied by prominent cranial parasympathetic signs and symptoms. There are very few studies in the literature on the evolution of childhood $\mathrm{CH}$. Maytal et al. [10], in a retrospective study, evaluated 35 patients with episodic and chronic $\mathrm{CH}$ arising at the age of 18 years or younger, including seven patients with onset prior to the age of 10 . The male-to-female ratio was $6: 1$. The patients were followed up for 18 years, and the clinical features of $\mathrm{CH}$ attacks in childhood were found to be similar to those that typically occur in adulthood. The frequency and duration of cluster periods and the frequency of single headache attacks during cluster periods increased in 14 subjects (40\%). Only two patients (6\%) reported a decrease in the duration of cluster periods. Very short cluster periods, of two weeks or less, occurred in $23 \%$ of patients during childhood and in $6 \%$ during adulthood. On comparison of cluster period duration in childhood versus adulthood in individual patients, 13 (37\%) patients showed longer-lasting cluster periods in adulthood, while only two (6\%) patients showed a decrease in the duration of cluster periods over time. A small number of patients noted changes in associated symptoms over the years. Of these, only six reported more symptoms in adulthood than in childhood and only one patient's symptoms shifted sides.

As regards the prevalence of $\mathrm{CH}$ in children, Lampl's epidemiological study [31] showed that pediatric $\mathrm{CH}$ is rare and that the prevalence of childhood onset (1118 years) is approximately $0.1 \%$. The case of a 7 -year old female who fulfilled the IHS diagnostic criteria for episodic $\mathrm{CH}$ was reviewed, but the paper in question did not provide data about evolution of the headache [31]. No differences in type of pain, associated symptoms and gender predominance (male) were found between childhood-onset $\mathrm{CH}$ and $\mathrm{CH}$ with onset in adolescence. When $\mathrm{CH}$ was left untreated the frequency and duration could increase or remain unchanged over time. Remissions, albeit brief ones, could occur, but spontaneous resolution of $\mathrm{CH}$ was rare.
According to our experience [48], $\mathrm{CH}$ has a prevalence of $0.09-0.1 \%$ in pediatric age, and the sex ratio is in favor of males (M/F: 3.2:1), albeit showing wide variation $(1: 1-6: 1)(31,47)$. Onset may occur as early as 3 years of age, although the number of cases with onset $<10$ years is relatively low. An atypical temporal pattern of episodic $\mathrm{CH}$ attacks was reported in an 11-year-old boy followed up for only nine months [48]. The first bout lasted eight months, and the second, in which the pain had the same characteristics, approximately two months. This patient could represent a 'variant' clinical picture.

In another prospective case report by Arruda et al. [49], three cases of $\mathrm{CH}$ in children and adolescents were discussed. Two of the patients had episodic $\mathrm{CH}$ (according to the ICHD-II criteria) and the other, affected by Down syndrome, had chronic unremitting $\mathrm{CH}$. In this study, the frequency and duration of the attacks reported in childhood were similar to those that have been reported in adults, both for episodic and chronic $\mathrm{CH}$. In two cases, a good response to indomethacin was observed, which makes the diagnosis questionable; moreover, sustained long-term medical and/or spontaneous remission occurred in two of the three patients.

\section{Discussion}

This review suggests that there is still a paucity of literature data on the evolution and prognosis of headache starting in childhood and adolescence.

The present review concerned studies conducted after the publication of the IHS (1988) and ICHD-II criteria $[17,41]$. Current studies in this field may have some limits due to the fact that the ICHD-II diagnostic criteria for migraine and TTH are excessively restrictive for young children (children may have a short migraine duration, bilateral presentation of migraine and they also present a wide variability of associated symptoms). Many children, in fact, fail to meet all the ICHD-II criteria and a diagnosis of probable migraine often has to be made; therefore, improved diagnostic criteria are needed [36].

Another possible limit is the difficulty in designing studies that consider the transition from childhood to adulthood, given relatively short follow-up periods involved. Moreover, the possible effect of hormonal changes in puberty on the changing phenotype of primary headache disorders (especially migraine) with increasing age might be not independent of other environmental factors, such as stress, family variables, comorbidities, and so on.

However, these studies have shown that while the reported frequency of migraine in children varies slightly from country to country and region to region, headache overall is a common phenomenon [37]. Moreover, all the analyzed studies were methodologically rigorous, in most cases using a retrospective study design. 
The discrepancies found between some studies may reasonably be attributed to several factors: differences in the number of headache patients enrolled, in the patient selection criteria - various populations were studied and different age ranges -, and in the sources of information used (parents versus child). In the past, a tendency toward parental underreporting of children's headache has been reported. In an epidemiological study of 3461 parent reports of children aged between 7 and 14 years, a high correlation was found between the children's and the parents' reports of children's headache frequency, but the correlations were much lower when other features were considered, with the parents' perception of depression and anxiety found to be the least reliable variable [50]. In addition, very young patients constitute a particular diagnostic challenge due to their limited verbal and language skills (which make it difficult to establish the site of pain and its quality) and also to the fact that headache in very young children is often a nonspecific complaint, associated with other illnesses.

There is a large consensus [51] that the natural temporal pattern of migraine may change over time: as attack frequency increases, the number of migraine features diminishes during the transformation period. At variance with what is observed in adults, adolescents with chronic daily headache have a temporal pattern with more migraine days than TTH [52]. It has also been shown that with increasing age, there is a decrease in the frequency of variables such as stress as a trigger, photophobia, phonophobia, dizziness, throbbing, pressure, stabbing, and being forced to sleep or rest during headache attacks. Factors that become more important with age are alcohol, smoking and neck pain as triggers, location of pain in the neck, and rhinorrhea/lacrimation [42]. Pediatric cases are often diagnosed as childhood periodic syndromes because children might not focus on their head pain, but rather on abdominal symptoms or vertigo. As they grow older their ability to describe their head pain improves and the description of the clinical picture of migraine becomes more detailed and accurate [53]. Pediatric migraine is more often bilateral, frontal and temporal than unilateral (35\% vs $60 \%$ in adults). The duration of the headache is often much shorter - it can last as little as 30 minutes - and there is a higher incidence of light or noise sensitivity than in adults [54].

At present it can, to the best of our knowledge, only be speculated that several factors contribute to the development of this pathophysiological trait. Hormonal changes, different levels of stress exposure, and the life events and circumstances behind each stress exposure may be only some of the factors contributing to a changing migraine phenotype over time.

Certain primary headaches may remit in a certain period, but the remission rate of headaches at shortterm follow-up cannot be considered indicative of a resolution pattern in the absence of parallel, long-term studies. When patients were followed up for 10 years or less, headaches were shown to improve or remit in $60-80 \%$ of cases [2]. Persistence of primary headache at 10-year follow-up appears to be more predictive of headache persistence into adulthood, particularly if the primary headache is migraine (40). Guidetti et al. [37] found that migraine showed a lower tendency than TTH to remit. Accordingly, Bille et al. [2] found that $23 \%$ of patients were migraine free at 23 years of age, while more than $50 \%$ continued to have migraines at the age of 50 years. The prognosis of headache in children is negatively affected if the initial diagnosis is migraine and they have a changing headache location. A negative outcome has been correlated with a longer time between headache onset and first medical consultation [54].

As regards the impact of sex hormones on migraine in women [55,56], some authors have analyzed [57] whether the onset of menarche affects the risk of developing migraine and headache frequency. An increased risk of headache was found in girls who had experienced menarche during the previous two years compared with girls yet to reach menarche. Aegidius et al. [58] examined the relationship between age at menarche and headache prevalence. The prevalence of headache was higher in girls with menarche at 12 years or younger than in those with menarche after the age of 12 years. In addition, they found a statistically significant trend toward decreasing prevalence of headache, migraine and TTH with increasing age at menarche. It was hypothesized that the inverse relationship between age at menarche and the prevalence of headache may be explained by a common pathogenetic factor such as sensitivity to estrogens, or by an increased susceptibility to headache due to early menarche. Hormonal changes as a migraine trigger were mainly observed in 30-50 year olds, and less in younger or older patients [42]. Hormonal changes might affect the pathophysiology of migraine in pediatric as in adult migraine and could partly explain the shift in predominance to girls during adolescence. Hormonal sensitivity is thought to be the basis for menstrual migraine $[59,60]$.

Genotype may also play a role in the complex picture of headache evolution. An early onset of disease probably reflects increased biological predisposition or increased susceptibility to specific environmental risk factors [57]. The high incidence of family antecedents in migraineurs has been used as an argument to support the existence of genetic factors in the etiopathogenesis of this type of headache $[59,61]$. The incidence of family antecedents has been found to be significantly higher in children who first presented symptoms at a younger age [37]. It is very likely that a greater genetic load plays an important role in earlier 
onset of migraine and may determine a worse prognosis. Nevertheless, this reasoning needs to be backed up by statistical data.

There remain open issues that the available literature fails to address, such as the question of drug response (persistence/change/absence of response) at different ages, both in symptomatic and prophylactic regimens, and of the placebo response and the question of medication overuse headache [62] in childhood. Other issues still to be clarified in pediatric subjects are the evolution of the aura phase during the natural history of migraine and the evolution of more than one type of headache in a single patient.

\section{Conclusions}

As shown by this systematic review, description of the evolution of headache from childhood to adulthood has been a focus of interest for several authors. The studies performed after the publication of the first IHS classification include both prospective and retrospective ones, the former being more reliable for defining the temporal pattern of headache. The availability of data about the evolution of primary headaches over a period of time is important, both from a clinical and a public health perspective. Indeed, the identification of prognostic factors of headache evolution over time should be an objective of future headache research to allow the development of prevention strategies. Headache may have a different incidence at different ages; a transition from migraine to other forms of headache or vice versa has been described; the clinical picture of migraine may change with age in some patients. However, we still lack sufficient data to assess whether these changes are hereditary or casual, and whether early abortive and prophylactic treatments play a role in the clinical shifts or in improvements of the temporal pattern.

As regards migraine, attacks in children are shorter lasting and present peculiar characteristics. The transition from childhood to adulthood brings a global lessening of the features of migraine is and a lower prevalence of migraine is observed in older patients. Approximately one in four migraine patients switched to TTH. Moreover, male gender is associated with remission, while early developmental disorders are associated with persistence of migraine. With increasing age, a decline in the frequency of variables such as stress as a trigger, and other pain characteristics or accompanying factors, was observed.

TTH is more likely than migraine to improve in the transition from childhood/adolescence to young adulthood. A switch to migraine was bserved in $25 \%$ of patients. As in migraine, male gender was found to be associated with remission and early developmental disorders to be associated with persistence.
$\mathrm{CH}$ is the type of headache on which least information is available, due to the relatively limited number of children affected. Episodic $\mathrm{CH}$ is more frequent than the chronic form. The frequency and duration of $\mathrm{CH}$ attacks in childhood are similar to those reported in adults. In the only retrospective study available, the frequency and duration of cluster periods and the frequency of single headache attacks during the bouts increased in less than $50 \%$ of patients as they approached adulthood.

More prospective studies following the evolution of headache into adulthood are required in order to achieve a deeper awareness of the different phenotypes of headache.

Competing interests

The authors declare that they have no competing interests.

\section{Authors' contributions}

$F A, C V I$, reviewed the literature and drafted the manuscript ADS, reviewed the literature $F G, A O, U B$ reviewed the manuscript and provided useful advice. All authors read and approved the final manuscript.

\section{Author details}

${ }^{1}$ Headache Center, C. Mondino National Institute of Neurology Foundation, IRCCS, University of Pavia, Pavia, Italy. ${ }^{2}$ State Medical and Pharmaceutical University "Nicolae Testemitanu", Chișinău, Republic of Moldova. ${ }^{3}$ University of Pavia, Pavia, Italy. ${ }^{4}$ C. Mondino National Institute of Neurology Foundation, IRCCS, Pavia, Italy. ${ }^{5}$ Department of Neurology, Mersin University School of Medicine, Mersin, Turkey. ${ }^{6}$ Child Neurology and Psychiatry Department, C. Mondino National Institute of Neurology Foundation, IRCCS, University of Pavia, Pavia, Italy.

Received: 9 January 2014 Accepted: 10 March 2014 Published: 18 March 2014

\section{References}

1. Vahlquist B, Hackzell G (1949) Migraine of early onset. Acta Paediatr 38:622-636

2. Bille B (1996) Migraine and tension-type headache in children and adolescents. Cephalalgia 16:78

3. Fearon P, Hotopf M (2001) Relation between headache in childhood and physical and psychiatric symptoms in adulthood: national birth cohort study. BMJ 322:1145

4. Passchier J, Orlebeke JF (1985) Headaches and stress in schoolchildren: an epidemiological study. Cephalalgia 5:167-176

5. Balottin U, Fusar-Poli P, Termine C, Molteni S, Galli F (2013) Psychopathological symptoms in child and adolescent migraine and tension-type headache: a meta-analysis. Cephalalgia 33:112-122

6. Wöber-Bingöl C (2013) Epidemiology of migraine and headache in children and adolescents. Curr Pain Headache Rep 17:341

7. Özge A, Bugdayci R, Sasmaz T, Kaleagasi H, Kurt O, Karakelle A, Tezcan H, Siva A (2002) The sensitivity and specificity of the case definition criteria in diagnosis of headache: a school-based epidemiological study of 5562 children in Mersin. Cephalalgia 22:791-798

8. Sillanpaa M, Piekkala P (1984) Prevalence of migraine and other headaches in early puberty. Scand J Prim Health Care 2:27-32

9. Anttila P, Metsähonkala L, Aromaa M, Sourander A, Salminen J, Helenius H, Alanen P, Sillanpää M (2002) Determinants of tension-type headache in children. Cephalalgia 22:401-408

10. Maytal J, Lipton RB, Solomon S, Shinnar S (1992) Childhood onset cluster headaches. Headache 32:275-279

11. Torelli P, Manzoni GC (2002) What predicts evolution from episodic to chronic cluster headache? Curr Pain Headache Rep 6:65-70

12. Kienbacher C, Wöber C, Zesch HE, Hafferl-Gattermayer A, Posch M, Karwautz A, Zormann A, Berger G, Zebenholzer K, Konrad A, Wöber-Bingöl C (2006) Clinical features, classification and prognosis of migraine and tension-type headache in children and adolescents: a long-term follow-up study. Cephalalgia 26:820-830 
13. Zuckerman B, Stevenson J, Bailey V (1987) Stomachaches and headaches in community sample of preschool children. Pediatrics 79:677-682

14. Wöber C, Wöber-Bingöl C (2000) Clinical management of young patients presenting with headache. Funct Neurol 15(Suppl 3):89-105

15. Guidetti VF, Galli F, Fabrizi P, Napoli L, Giannantoni AS, Bruni O, Trillo S (1998) Headache and psychiatric comorbidity: clinical aspects and outcome in an 8-year follow-up study. Cephalalgia 18:455-462

16. Newacheck PW, Taylor WR (1992) Childhood chronic illness: prevalence, severity, and impact. Am J Public Health 82:364-371

17. Headache Classification Committee of the International Headache Society (1988) Classification and diagnostic criteria for headache disorders, cranial neuralgias and facial pain. Cephalalgia 8:1-96

18. Akyol A, Kiylioglu N, Aydin I, Erturk A, Kaya E, Telli E, Akyildiz U (2007) Epidemiology and clinical characteristics of migraine among school children in the Menderes region. Cephalalgia 27:781-787

19. Karli N, Akgoz S, Zarifoglu M, Akis N, Erer S (2006) Clinical characteristics of tension- type headache and migraine in adolescents: a student-based study. Headache 46:399-412

20. Sillanpää M, Piekkala P, Kero P (1991) Prevalence of headache at preschool age in an unselected child population. Cephalalgia 11:239-242

21. Sillanpää M (1983) Changes in the prevalence of migraine and other headaches during the first seven school years. Headache 23:15-19

22. Lipton RB, Maytal J, Winner P (2001) Epidemiology and classification of Headache. In: Winner P, Rothner AD (ed) Headache in children and adolescents. BC Decker Inc, Hamilton, pp 87-115

23. Bugdayci R, Ozge A, Sasmaz T, Kurt AO, Kaleagasi $H$, Karakelle A, Tezcan H, Siva A (2005) Prevalence and factors affecting headache in Turkish schoolchildren. Pediatr Int 47:316-322

24. Guidetti V, Galli F, Termine C (2011) Headache in Children. In: Aminoff MJ, Boller F, Swaab D (ed) Handbook of Clinical Neurology. Vol. 97: Nappi G, Moskowitz M. eds. Headache. Elsevier, Amsterdam

25. Carlsson J (1996) Prevalence of headache in schoolchildren: relation to family and school factors. Acta Paediatr 85:692-696

26. Abu-Arafeh I, Razak S, Sivaraman B, Graham C (2010) Prevalence of headache and migraine in children and adolescents: a systematic review of population- based studies. Dev Med Child Neurol 52:1088-1097

27. Stewart WF, Lipton RB, Celentano DD, Reed ML (1992) Prevalence of migraine headache in the United States. Relation to age, income, race, and other sociodemographic factors. JAMA 267:64-69

28. Ekbom K (1970) A clinical comparison of cluster headache and migraine. Acta Neurol Scand 46(Suppl 41):1-44

29. Lance JW, Anthony M (1971) Migrainous neuralgia or cluster headache? J Neurol Sci 13:401-414

30. Terzano MG, Manzoni GC, Maione R (1981) Cluster headache in one year old infant? Headache 21:255-256

31. Lampl C (2002) Childhood-onset cluster headache. Pediatr Neurol 27:138-140

32. Antonaci F, Sjaastad O (1989) Chronic paroxysmal hemicrania (CPH): a review of the clinical manifestations. Headache 29:648-656

33. Lewis D, Gozzo Y, Avner M (2005) The "other" primary headaches in children and adolescents. Pediatr Neurol 33:303-313

34. Benoliel R, Sharav Y (1998) Paroxysmal hemicrania. Oral Surg Oral Med Ora Pathol Oral Radiol Endod 85:285-292

35. Antonaci F, Pareja JA, Caminero AB, Sjaastad O (1998) Chronic paroxysmal hemicrania and hemicrania continua: lack of efficacy of sumatriptan. Headache 38:197-200

36. Özge A, Termine C, Antonaci F, Natriashvili S, Guidetti V, Wöber- Bingöl C (2011) Overview of diagnosis and management of pediatric headache. Part I: diagnosis. J Headache Pain 12:13-23

37. Guidetti V, Galli F (1998) Evolution of headache in childhood and adolescence: an 8-year follow-up. Cephalalgia 18:449-454

38. Hernandez-Latorre MA, Roig M (2000) Natural history of migraine in childhood. Cephalalgia 20(6):573-579

39. Brna P, Dooley J, Gordon K, Dewan T (2005) The prognosis of childhood headache: a 20-year follow-up. Arch Pediatr Adolesc Med 159:1157-1160

40. Balottin U, Termine C, Nicoli F, Quadrelli M, Ferrari-Ginevra O, Lanzi G (2005) Idiopathic headache in children under six years of age: a follow-up study. Headache 45:705-715

41. Headache Classification Subcommittee of the International Headache Society (2004) The international classification of headache disorders, 2nd edition. Cephalalgia 24(Suppl. 1):9-160
42. Kelman $L$ (2006) Migraine changes with age: IMPACT on migraine classification. Headache 46:1161-1171

43. Virtanen $R$, Aromaa M, Rautava $P$, Metsähonkala $L$, Anttila $P$, Helenius $H$, Sillanpää M (2007) Changing headache from preschool age to puberty. A controlled study. Cephalalgia 27:294-303

44. Gassmann J, Morris L, Heinrich M, Kröner-Herwig B (2008) One-year course of paediatric headache in children and adolescents aged 8-15 years. Cephalalgia 28:1154-1162

45. Slater S, Crawford MJ, Kabbouche MA, LeCates SL, Cherney S, Vaughan P, Segers A, Manning P, Burdine D, Powers SS, Hershey AD (2009) Effects of gender and age on paediatric headache. Cephalalgia 29:969-973

46. Ozge A, Sasmaz T, Cakmak SE, Kaleagasi H, Siva A (2010) Epidemiologicalbased childhood headache natural history study: after an interval of six years. Cephalalgia 30:703-712

47. Wöber-Bingöl C, Wöber C, Karwautz A, Auterith A, Serim M, Zebenholzer K, Aydinkoc K, Kienbacher C, Wanner C, Wessely P (2004) Clinical features of migraine: a cross-sectional study in patients aged three to sixty-nine. Cephalalgia 24:12-17

48. Antonaci F, Alfei E, Piazza F, De Cillis I, Balottin U (2010) Therapy-resistant cluster headache in childhood: case report and literature review. Cephalalgia 30:233-238

49. Arruda MA, Bonamico L, Stella C, Bordini CA, Bigal ME (2011) Cluster headache in children and adolescents: ten years of follow-up in three pediatric cases. Cephalalgia 31:1409-1414

50. Kroner-Herwig B, Morris L, Heinrich M, Gassmann J, Vath N (2009) Agreement of parents and children on characteristics of pediatric headache, other pains, somatic symptoms, and depressive symptoms in an epidemiologic study. Clin J Pain 25:58-64

51. Stewart WF, Staffa J, Lipton RB, Ottman R (1997) Familial risk of migraine: a population-based study. Ann Neurol 41:166-172

52. Bigal ME, Arruda MA (2010) Migraine in the pediatric population—evolving concepts. Headache 50:1130-1143

53. Hershey AD (2010) Current approaches to the diagnosis and management of paediatric migraine. Lancet Neurol 9:190-204

54. Evans RW (2007) Headache During Childhood and Adolescence. In: Handbook of Headache. , Philadelphia, pp 209-299

55. MacGregor EA (2012) Classification of perimenstrual headache: clinical relevance. Curr Pain Headache Rep 16(5):452-460

56. Lieba-Samal D, Wöber C, Frantal S, Brannath W, Schrolnberger C, Wöber-Bingöl C, PAMINA study group (2011) Headache, menstruation and combined oral contraceptives: a diary study in 184 women with migraine. Eur J Pain 15:852-857

57. Kröner-Herwig B, Vath N (2009) Menarche in girls and headache-a longitudinal analysis. Headache 49:860-867

58. Aegidius KL, Zwart JA, Hagen K, Dyb G, Holmen TL, Stovner LJ (2011) Increased headache prevalence in female adolescents and adult women with early menarche. The Head-HUNT Studies. Eur J Neurol 18:321-328

59. Martin VT, Behbehani M (2006) Ovarian hormones and migraine headache: understanding mechanisms and pathogenesis_part I. Headache 46:3-23

60. Merikangas KR (1990) Genetic Epidemiology of Migraine. In: Sandler M, Collins GM (ed) Migraine: A Spectrum of Ideas. Oxford University Press, New York, pp 40-47

61. Martin VT, Behbehani M (2006) Ovarian hormones and migraine headache: understanding mechanisms and pathogenesis_-part 2. Headache 46:365-386

62. Piazza F, Chiappedi M, Maffioletti E, Galli F, Balottin U (2012) Medication overuse headache in school-aged children: more common than expected? Headache 52:1506-1510

\section{doi:10.1186/1129-2377-15-15}

Cite this article as: Antonaci et al:: The evolution of headache from childhood to adulthood: a review of the literature. The Journal of Headache and Pain 2014 15:15. 